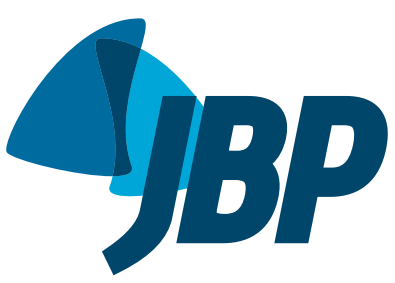

\title{
Global TB Network: working together to eliminate tuberculosis
}

\author{
Denise Rossato Silva ${ }^{1, a}$, Adrian Rendon²,b, Jan-Willem Alffenaar ${ }^{3, c}$, \\ Jeremiah Muhwa Chakaya ${ }^{4,5, d}$, Giovanni Sotgiu' ${ }^{6, e}$, Susanna Esposito7,f, \\ Giovanni Battista Migliori ${ }^{8, \mathrm{~g}}$
}

In spite of the global efforts of the World Health Organization (WHO) and partners to reduce the incidence of tuberculosis (about 2\% per year) and its mortality (about 3\% per year), the disease is still a global killer and has primary public health importance, with an estimate of 10.4 million cases in 2016. ${ }^{(1)}$

The End TB Strategy and its vision (zero tuberculosisrelated deaths, cases, and suffering) underlies the possibility to eliminate tuberculosis as a public health priority in countries with a low incidence of tuberculosis..$^{(2-4)}$ Pillar 2 of the End TB Strategy clearly emphasizes the importance of collaboration at different levels. This international collaboration represents the last of the eight core areas to pursue tuberculosis elimination. ${ }^{(4)}$

Translating that into simple words, international collaboration comprises all of the interactions involving clinicians, laboratory staff, public health officers, national tuberculosis programs, other programs (HIV/AIDS programs and diabetes programs in some countries), Ministries of Health (as well as Ministries of Justice for jails/prisons, Ministries of Interior for the migration-related issues, Ministries of Transportation, etc), private sector, pharmaceutical sector, civil society, representatives of the affected communities, and international organizations, among others. ${ }^{(4,5)}$

As of today, several TB Networks exist: the Stop TB Partnership ${ }^{(6)}$ has a long tradition in supporting advocacy. In addition, one of the best examples is the Brazilian Rede $T B$, which shows that the best research efforts, even in a large country as is Brazil, can collaborate to solve country-specific priorities and involve national tuberculosis programs and authorities in the plan..$^{(7-11)}$ However, as of today, no global tuberculosis network is operational enough to put together all of the abovementioned actors in order to support the fight against tuberculosis.

To respond to this need, the Global TB Network* (GTN) will be launched at the second Conference of the World Association for Infectious Diseases and Immunological Disorders (WAidid), ${ }^{(12)}$ which will take place in the city of Milan, Italy, from October 18-20 of 2018, involving an international group of experts and covering a wide range of perspectives.
The goal of the GTN is to pursue tuberculosis elimination with a global effort proactively, building on existing collaborations in the area of research, advocacy, and training. Its core objectives are to foster and conduct research on key unmet therapeutic and diagnostic needs in the field of tuberculosis elimination, leveraging on multidisciplinary, multisectoral approaches and supportive interventions (i.e., training and advocacy activities) within the framework of the WHO End TB Strategy. Preliminary plans propose to focus on latent tuberculosis infection, multidrug- and extensively drug-resistant tuberculosis rapid diagnosis, and other neglected areas (pediatric tuberculosis, extrapulmonary tuberculosis, rehabilitation of tuberculosis sequelae, infection control, etc.)

The GTN represents the structured evolution of pre-existing global tuberculosis networks, including the international linezolid, carbapenems and bedaquiline study groups and the International Severe Cases and Rehabilitation Study Group, which produced over 40 articles in the last five years in impact-factor, peer-reviewed journals, as well as various series on tuberculosis in different journals in collaboration with scientific societies, such as the European Respiratory Society, Sociedade Brasileira de Pneumologia e Tisiologia, and the Asociación Latinoamericana del Tórax. ${ }^{(13-18)}$

This new global network aims at collaborating with existing organizations, associations, institutions, and partners that are committed to fight against tuberculosis by complementing and boosting (and not duplicating) the existing initiatives.

The GTN is hosted by WAidid, ${ }^{(12)}$ founded in July of 2014 in order to advance the scientific research in the field of infectious diseases and immunology and to disseminate information on the related pathologies. WAidid is the response to the previous lack of a network that links associations and scientific societies focused on infections, vaccines, and immunology. WAidid, whose membership is free of charge, represents the bridge for a global multidisciplinary approach to infections (including tuberculosis) operating across all age groups.

The GTN is composed of three pillars:

1. Faculdade de Medicina, Universidade Federal do Rio Grande do Sul, Porto Alegre (RS) Brasil.

2. Centro de Investigación, Prevención y Tratamiento de Infecciones Respiratorias, Hospital Universitario, Universidad de Monterrey, Monterrey, México.

3. Department of Clinical Pharmacy and Pharmacology, University Medical Center Groningen, University of Groningen, Groningen, the Netherlands.

4. Union Headquarters, International Union Against Tuberculosis and Lung Disease, Paris, France.

5. Department of Medicine, Therapeutics, Dermatology and Psychiatry, Kenyatta University, Nairobi, Kenya.

6. Sezione di Epidemiologia Clínica e Statistica Medica, Dipartimento di Scienze Mediche, Chirurgiche e Sperimentali, University degli Studi di Sassari, Sassari, Italia

7. Sezione di Pediatria generale e specialistica, Dipartimento di Scienze Chirurgiche e Biomediche, Università degli Studi di Perugia, Perugia, Italia.

8. Istituti Clinici Scientifici Maugeri, Istituto di Ricovero e Cura a Carattere Scientifico - IRCCS - Tradate, Italia.

a. (ID) http://orcid.org/0000-0003-0230-2734; b. (iD) http://orcid.org/0000-0001-8973-4024; c. (iD) http://orcid.org/0000-0001-6703-0288;

d. (iD http://orcid.org/0000-0002-3229-2429; e. (iD) http://orcid.org/0000-0002-1600-44740; f. (iD) http://orcid.org/0000-0003-4103-2837;

g. (iD http://orcid.org/0000-0002-2597-574X 
Pillar 1 includes the Technical Committees covering the main areas relevant to tuberculosis and nontuberculous mycobacteriosis management (Tuberculosis Prevention/Latent Tuberculosis Infection; Tuberculosis Diagnosis; Tuberculosis Treatment; Tuberculosis Pharmacology; Pediatric Tuberculosis; Migrants/Vulnerable Populations; Nontuberculous Mycobacteriosis; Tuberculosis Infection Control; Impact Evaluation, Strategies \& Global Health; Clinical Support to Patients (Tuberculosis Consilium); Clinical Trials; Tuberculosis and Surgery; Basic Science; and Epidemiology, Statistics and Methodology).

Pillar 2 includes representatives from each association/organization active in tuberculosis control interested in participating in the GTN.

Pillar 3 includes the private and pharmaceutical sectors.

Several global projects have already started, including an online clinical service aimed at supporting the correct management of difficult-to-treat tuberculosis cases and of individuals with latent tuberculosis infection, as well as the rational introduction of new drugs; a project monitoring adverse events of new antituberculosis drugs; one study on tuberculosis and surgery; and one study on tuberculosis sequelae and rehabilitation.

We hope this initiative will contribute to reaching the ambitious goals of the End TB Strategy.

\section{*Global TB Network provisional Steering Committee:}

Chair: Giovanni Battista Migliori

Secretary General: Denise Rossato Silva
Other Members: Jan-Willem Alffenaar, Jeremiah Muhwa Chakaya, Adrian Rendon, Daniela M. Cirillo, James Chalmers, Sergey Borisov, Erlina Buran, Isabel Saraiva, Masae Kawamura (Observer)

\section{Global TB Network Secretariat}

Secretariat in Tradate (Italy): Rosella Centis, Lia D'Ambrosio, Dina Visca, Antonio Spanevello

Secretariat in Milano (Italy): Elisabetta Di Felice

\section{Global TB Network Chairs of Committees}

TB Pharmacology Committee: Jan-Willem Alffenaar

Epidemiology, Statistics and Methodology Committee: Giovanni Sotgiu

TB Prevention/LTBI Committee: Delia Goletti

TB Diagnosis Committee: Daniela Maria Cirillo

TB Treatment Committee: Marcela Muňoz Torrico

Paediatric TB Committee: Ben Marais

Migrants/Vulnerable Populations Committee: Claudia Dobler

NTM Committee: James Chalmers

TB Infection Control Committee: Edward Nardell

Impact Evaluation, Strategies \& Global Health Committee: Alberto Garcia Basteiro

Clinical Support to Patients (TB Consilium): Marina Tadolini

Clinical Trials Committee: Emanuele Pontali

TB and Surgery Committee: Alessandro Mariani

Basic Science Committee: Tom H.M. Ottenhoff

World Association for Infectious Diseases and Immunological Disorders (WAidid): President: Susanna Esposito

\section{REFERENCES}

1. World Health Organization. Global tuberculosis report 2017. Geneva: World Health Organization; 2017

2. Lönnroth K, Migliori GB, Abubakar I, D'Ambrosio L, de Vries G, Diel $R$, et al. Towards tuberculosis elimination: an action framework for low-incidence countries. Eur Respir J. 2015;45(4):928-52. https://doi. org/10.1183/09031936.00214014

3. D'Ambrosio L, Dara M, Tadolini M, Centis R, Sotgiu G, van der Werf MJ, et al. Tuberculosis elimination: theory and practice in Europe. Eur Respir J. 2014;43(5):1410-20. https://doi. org/10.1183/09031936.00198813

4. Duarte R, Silva DR, Rendon A, Alves TG, Rabahi MF, Centis R, et al. Eliminating tuberculosis in Latin America: making it the point. Bras Pneumol. 2018;44(2):73-76 https://doi.org/10.1590/s1806 37562017000000449

5. Silva DR, Mu-oz-Torrico M, Duarte R, Galvão T, Bonini EH, Arbex FF et al. Risk factors for tuberculosis: diabetes, smoking, alcohol use, and the use of other drugs. J Bras Pneumol. 2018:44(2):145-152. https://doi.org/10.1590/s1806-37562017000000443

6. Stop TB Partnership [homepage on the Internet]. Geneva: Stop TB Partnership; c2018 [updated 2018 Aug 31; cited 2018 Aug 31] Available from: http://www.stoptb.org/

7. Kritski A, Dalcolmo MP, Mello FCQ, Carvalho ACC, Silva DR, Oliveira MM, et al. The role of the Brazilian Tuberculosis Research Network in national and international efforts to eliminate tuberculosis. J Bras Pneumol. 2018;44(2):77-81. https://doi.org/10.1590/s180637562017000000435

8. Navarro PD, Almeida IN, Kritski AL, Ceccato MD, Maciel MM
Carvalho WD, et al. Prevalence of latent Mycobacterium tuberculosis infection in prisoners. J Bras Pneumol. 2016;42(5):348-355. https:// doi.org/10.1590/S1806-37562016000000001

9. Moreira Ada S, Huf G, Vieira MA, Fonseca L, Ricks M, Kritski AL. Performance comparison between the mycobacteria growth indicator tube system and Löwenstein-Jensen medium in the routine detection of Mycobacterium tuberculosis at public health care facilities in Rio de Janeiro, Brazil: preliminary results of a pragmatic clinical trial. J Bras Pneumol. 2013:39(3):365-7. https://doi. org/10.1590/S1806-37132013000300014

10. Ramalho DMP, Miranda PFC, Andrade MK, Brígido T, Dalcolmo MP Mesquita $E$, et al. Outcomes from patients with presumed drug resistant tuberculosis in five reference centers in Brazil. BMC Infect Dis. 2017;17(1):571. https://doi.org/10.1186/s12879-017-2669-1

11. de Almeida IN, de Assis Figueredo LJ, Soares VM, Vater MC, Alves S, da Silva Carvalho W, et al. Evaluation of the Mean Cost and Activity Based Cost in the Diagnosis of Pulmonary Tuberculosis in the Laboratory Routine of a High-Complexity Hospital in Brazil. Front Microbiol. 2017;8:249. https://doi.org/10.3389/fmicb.2017.00249

12. World Association for Infectious Diseases and Immunological Disorders (WAidid) [homepage on the Internet]. Milan: WAidid c2014 [updated 2018 Aug 31; cited 2018 Aug 31]. Available from: http://www.waidid.org/

13. Borisov SE, Dheda K, Enwerem M, Romero Leyet R, D’Ambrosio $L$, Centis $R$, et al. Effectiveness and safety of bedaquilinecontaining regimens in the treatment of MDR- and XDR-TB: a multicentre study. Eur Respir J. 2017;49(5). pii: 1700387. https://doi. org/10.1183/13993003.00387-2017 
14. Tiberi S, Sotgiu G, D'Ambrosio L, Centis R, Abdo Arbex M, Alarcon Arrascue $E$, et al. Comparison of effectiveness and safety of imipenem/clavulanate- versus meropenem/clavulanate-containing regimens in the treatment of MDR- and XDR-TB. Eur Respir J. 2016;47(6):1758-66. https://doi.org/10.1183/13993003.00214-2016

15. Tiberi S, Payen MC, Sotgiu G, D'Ambrosio L, Alarcon Guizado $V$, Alffenaar JW, et al. Effectiveness and safety of meropenem/ clavulanate-containing regimens in the treatment of MDRand XDR-TB. Eur Respir J. 2016;47(4):1235-43. https://doi. org/10.1183/13993003.02146-2015

16. Tiberi S, Sotgiu G, D'Ambrosio L, Centis R, Arbex MA, Alarcon Arrascue E, Alffenaar JW, et al. Effectiveness and Safety of Imipenem-Clavulanate Added to an Optimized Background Regimen
(OBR) Versus OBR Control Regimens in the Treatment of Multidrug Resistant and Extensively Drug-Resistant Tuberculosis. Clin Infect Dis. 2016;62(9):1188-90. https://doi.org/10.1093/cid/ciw088

17. Borisov SE, D'Ambrosio L, Centis R, Tiberi S, Dheda K, Alffenaar JW, et al. Outcomes of patients with drug-resistant-tuberculosis treated with bedaquiline-containing regimens and undergoing adjunctive surgery. J Infect. 2018 Aug 7. pii: S0163-4453(18)30246-9. https:// doi.org/10.1016/j.jinf.2018.08.003

18. Munoz M, Tiberi S, Gomez R, Carvalho A, Cordeiro dos Santos M Ferreira D, et al. Desenlaces de casos graves de tuberculosis en América Latina y Europa [Abstract]. In: Vásquez García JC, editor. Proceedings of the 11th Congreso ALAT (Asociación Latinoamericana del Tórax); 2018 Jun 27-30; Ciudad de México, Mexico; 2018. 